\title{
Crisis Communication as Trust Repair Strategy in the Fast Food Industry Comparison of Case Studies
}

\author{
Wasfi Alrawabdeh \\ The Hashemite University \\ Ahmad Fathi Alheet
Al-Ahliyya Amman University \\ Mohammad Al-Dwiry \\ The Hashemite University \\ Abdullah Yousef Fayad Bani Hamand \\ Al-Ahliyya Amman University
}

\begin{abstract}
Crisis communication strategies can effectively contribute to reducing the harmful impacts of crisis on business performance. This research paper, in the context of fast food industry, discusses how effective crisis communication can act as a trust repair strategy. Using the cases of McDonald's and KFC in China and applying discourse analysis technique, the study found comparatively McDonald's had a better response strategy to the food crises, which resulted in restoring trust and positive image. On the other hand, KFC found itself in a very unsatisfactory position and took a year to regain its status in the fast-food industry.
\end{abstract}

Keywords: Crisis communication, trust repair strategy, food safety, McDonald's, KFC, Fast Food Industry

\section{Introduction}

\subsection{Background}

First the new in this research is that the authors put the outcome of comparing the actions of international companies in crisis communications and their role in repairing the customres trust through comparisons of methods and strategies in McDonalds and KFC. And the challenge and gap was in identifying the considerations made by fast-food business, during selecting the post-crisis communication strategies and this research came up to bridge this gap and challenge.

Food safety crisis is a significant and unpredictable event, which is likely to cause food-borne illness (McEvoy, 2016). The safety crisis within the food industry is not limited to the developing countries of the world; rather, the crisis is also reported among the developed countries of the world. Crisis in the food industry does not only influence the service users of the food industry, but also negatively influence the employees, products, services, reputation, and financial conditions of the organisation preparing food (Yan, 2011). However, most often food crisis is discussed with reference to the harmful impacts on health and well-being of the consumers (Wu and Ding, 2014). Despite having negative influence on health of consumers, the food crisis also affects the trust levels of the consumers (Yeung and Yee, 2012). The food safety crisis can also lead the company towards irreversible losses, i.e., loss of brand image; hence, leading the company towards bankruptcy. The consequences of food safety crisis and incidences are not only limited to the firm that is directly involved in the scandal; rather, report of food safety events also influence the operations and reputation of the entire food industry (Mørkbak et al. 2010). In this regard, the crisis has far-reaching consequences for the internal and external stakeholders of the organisation (McEvoy, 2016). Therefore, to avoid such situations it is important for the food companies to establish well-defined postcrisis communication strategies.

According to Zhu, Anagondahalli, and Zhang (2017), the post-crisis communication strategies utilised by the business firms are likely to mitigate and exacerbate the outcomes of the crisis. For this reason, the crisis communication strategies selected by the business firms can effectively contribute in reducing the harmful impacts of crisis on business performance, specifically by communicating justified conditions that resulted to crisis situation (Veil, Buehner, and Palenchar, 2011). Discussing the crisis communication strategies utilised by KFC and McDonalds, Zhu, Anagondahalli, and Zhang (2017) mentioned that the utilisation of social media platform for carrying out post-crisis communication was an effective strategy for clarifying the reasons of food crisis among the potential consumers. Reporting the KFC and McDonald's crisis, Hu, and Xie (2013) stated that the food-related discussion resulted in heated debates; therefore, the utilisation of same media for providing immediate response from the management is likely to effectively contribute in restoring brand image and reputation of the brand 
(Hu and Xie, 2013). On the basis of this evidence, it can be stated that crisis responses strategies are required to be implemented after carrying out the assessment of cultural beliefs of the customers. It is due to the fact that different response communication strategies are likely to be effective in different cultures. Moreover, in this era of technology, the pace and rate of transfer of information have been increasing rapidly, which can either create more challenging situations or create opportunities for the businesses. For this reason, after experiencing crisis, the business firms are required to focus on the implementation of effective crisis communication strategies for protecting the reputation of the firm.

Study novelty is represented in reaching new results, as mentioned in this research, of the role of communication with customers and its role in achieving reform and recovery from crises for organizations.

\subsection{Problem Statement}

With the improvement in health-related knowledge, the consumers of the fast-food industry are more focused towards food safety. For this reason, food crisis experienced by the fast-food company is likely to reduce the number of consumers. Due to this reason, after experiencing a food crisis, the food industries focus on maintaining their customer base by providing response to the crisis. The strategies utilised within the food industry is likely to have significant influence on their reputation; therefore, it is significant to analyse the factors which are considered by the business firms prior to selecting crisis management strategies. McEvoy, (2016) and Zhu, Anagondahalli, and Zhang (2017) have considered the significance of post-crisis communication for preventing further negative influence on the reputation of the firm; however, there is gap in research identifying the considerations made by fast-food business, during selecting the post-crisis communication strategies. This research will bridge this gap and will also include in-depth analysis of the post-crisis management strategies that are utilised by the well-known brands, operating in the fast-food industry. This research will describe the extent to which the crisis communication strategies, utilised by business firms, can repair the trust of the consumers and mitigate the negative impacts of food crises.

The research Procedure adopted for the current study is qualitative in nature. The authores used Comparison of case studies in McDonald and KFC.

\subsection{Aims and Objectives}

This research aims to analyse the extent to which crisis communication can be utilised as a trust-repair strategy in the fast-food industry. The objectives of this research are listed below.

1. To discover how crisis communication strategies can mitigate negative impacts on the reputation of the organisation belonging to the fast-food industry.

2. To evaluate and compare crisis communication strategies utilised by well-known organisations of the fast-food industry.

\section{Literature Review}

\subsection{Crisis Communication}

Crisis is Influence of a situation or event that challenges an individual's forces and forces him to change his point of view and re-adapt to himself or with the outside world or with both(Buklemishev,2020)

A crisis can be defined as a way any organisation or a person discerns an unforeseen event (Coombs, 2014). Crisis, particularly the ones that cannot be avoided, is a potential threat to the reputation of the organisation as well as to the social, economic, and environmental conditions of the society. In this account, crises communication can help organisations in effectively handling the situation. According to the study of Utz, Schultz, and Glocka (2013), the main objective of crisis communication is to rebuild the trust of stakeholders or customers and reclaim the organisation's reputation. In other words, it can be affirmed that crisis communication is associated with the use of communication strategies to reduce the damage inflicted and overcome the crisis (Timothy Coombs and Jean Holladay, 2014).

According to the study of Sellnow and Seeger (2013), crisis communication not only has roots in public relations and crisis management, but it also deals with handling crises situations that are occurred in an organisational environment. The study of Steelman and McCaffrey (2013) proclaims that crisis communication should be taken into consideration, throughout all the stages of crisis management. The study further highlighted that crisis communication highlights important features such as public being treated as legitimate partners, pre-event planning, comprehending public concerns, acknowledgement of uncertainties, honest communication, and providing solid actions that people can take. Veil and Husted (2012) have highlighted that the best practices in crisis management are an effective way of improving the efficiency and quality of the food chain. In particular, these practices include prompt response, accept uncertainty, the establishment of crisis communication networks, listening to public concerns, and so on. The study of Coombs (2015) also found that to increase the effectiveness of crisis communication, four factors play a significant role. 
These factors include reinforcement, response, preparation, and prevention. On the basis of this evidence, it can be affirmed that effective crises communication strategies could help organisations in restoring their lost repute and public image.

\subsection{Strategy for Crisis Communication}

Communication is the key to resolve the crisis, specifically by sharing transparent and correct information. To gain in-depth insights, some of the commonly employed crises communication strategies are discussed in the following sections.

\subsubsection{Crisis Timing Strategies}

In times of crisis, open communication might result in increasing the intensity of conflicts. However, Claeys, Cauberghe and Leysen (2013) emphasise the significance of proactive and open communication during the time of crises. In this account, organisations have the option of choosing between two strategies for crisis timing, namely ex-post crisis timing strategy and ex-ante crisis timing strategy. According to the study of Claeys and Cauberghe (2012), the latter is a self-disclosure strategy and frequently refer to as stealing thunder where organisation inform its stakeholders about a crisis, before any other group (like media or government) does. The former, however, is referred to as thunder in which organisations respond to media or other third parties' queries. According to the research of Claeys, Cauberghe, and Leysen (2013), strategies on crisis timing were originated in the context of the lawsuits. The study further proclaims that crisis communication within an organisation is less effective if it keeps on getting delayed. In addition, the ex-ante crisis timing strategy is considered to have a positive public relation as it enables stakeholders to consider the crisis being less harmful.

The effectiveness of ex-ante crisis timing strategy can be demonstrated by multiple theories. The commodity theory is the first theory which, according to Fehrenbacher (2016), is the psychological effects of scarcity the organization's worth to consumers. The scarcer the information about a particular issue, the more precious it is to the general public. Another theory is the disconfirmation of expectations theory that elaborates the user's process of expectations, trial, disconfirmation, and formation of expectations that contribute to the continuance and satisfactory intentions (Lankton, McKnight, and Thatcher, 2014). These expectations are disconfirmed by the exante crisis timing strategy while increasing the authenticity and credibility of both organization and spokesperson. The last one is the framing theory that suggests that by using crisis timing strategies, organisations are able to communicate the crisis with respect to their conditions while lessening its gravity (Ardèvol-Abreu, 2015).

\subsubsection{Crisis Response Strategy}

The concept of Situational Crisis Communication Theory (SCCT) is quite different from other frameworks. Kim and Sung (2014) have highlighted that SCCT matches the strategies of crisis response to types of crisis situations. This information is later used to give direction regarding the best-suited strategy. Utz, Schultz, and Glocka (2013) have also highlighted this characteristic of SCCT by claiming that it focuses on suggesting optimal crises response strategy to the businesses, by thoroughly considering the type and nature of the crises. In addition to this, SCCT also differentiates crisis into three clusters: the accidental, victim, and intentional or preventable. In this account, Coombs (2015) has indicated that SCCT provides managers with response strategy options to counter the crisis. In this context, crisis communication strategies are categorised into two types, including managing to mean and managing information. The latter is associated with the dissemination and collection of information related to the crisis. The former, however, refers to influencing people's perceptions about a crisis or organisation's involvement in the crisis. In short, it can be contended that crisis response strategy is mainly about managing to mean. Thus, crisis response strategies must consider the impacts on stakeholder's perception of a crisis.

The study conducted by Claeys and Cauberghe (2014) has stated that in the situation of preventable crises, crisis managers are advised to choose such crisis response strategies that have the same potential to counter the conflicting situation. In addition to this, Ma and Zhan (2016) found that SCCT is built on image repair theory and attribution theory. The study further states that public attribution damages the organisation's reputation; therefore, an organization's response strategies, to restore its reputation, should match the level of attributed responsibility. In light of these findings, it can be contended that it allows the managers in finding substitutes so as to reduce the intensity of reputation damages.

\subsection{PR Practice in Crisis Communication}

In the area of communication crisis, developing public relations (PR) help organisations in enhancing the efficacy of the disseminated information. It is due to the fact that this strategy allows the organisations to share crises related information to the target audience, without having the need for having journalists or any other media channel. According to Veil and Husted (2012), and Gillespie and Dietz (2009), a few of the best practices that could be potentially adopted by the organisations to use as a crisis communication strategy are described as follows: 


\subsubsection{Immediate Responses}

According to Gillespie and Dietz (2009), urgent and critical steps should be taken in case of crisis to handle the situation in an efficient manner. In more precise words, the organization must clearly communicate its stakeholders about the failure and all underlying reasons. As mentioned by Veil and Husted (2012), it is the first step to restore the reputation and its importance cannot be denied at any cost. In light of these findings, it can be stated that organisations should take immediate response to the crises instead of waiting for too long.

\subsubsection{Partnership with and Listen to Audience}

Public relations practices serve as a centre point for creating strong and long-term relationships with the public. According to the study of Janoske, Liu and Madden (2013), establishing customers relationships act as a glue, if relationships are removed from the equation, there will be bigger problems with recovery. The study further highlights that during the time of crisis, stakeholders and organisations are the key players that could make a great impact. As mentioned by Veil and Husted (2012), engaging with local communities and partnering with responsible organizations will not only help organisations in restoring stakeholder's trust, but it will also develop a strong relationship with different populations. Likewise, Janoske, Liu, and Madden's (2013) stated that the organization's concern may not exactly be the same as a public concern. These concerns are a combination of outrage and hazard. Therefore, If the hazard is low and the outrage is high, it is the responsibility of an organization to acknowledge and address the outrage. However, in the other situation, proper warnings should be given to the public regarding the crises; hence, resulting in gaining their trust.

\subsection{Trust Repairing Strategies in the light of Trust-Oriented Augmentation Theory}

Palmieri and Musi (2019) proposed a trust-repair strategy, in the context of crisis communication, which is known as argumentation theory. Argumentation theory is one of the theories that help in assessing and understanding the trust (McMurphy, 2013). The study of Fuoli and Paradis (2014) defines trust as a fundamental component of distant and interpersonal relations. Therefore, in an event where trust is undermined, redeeming actions are expected from a trust breaker. Since trust is an important element, the company's social survival and legitimacy are questioned if the trust is damaged between the company and stakeholders. The study of McMurphy (2013) found that argumentation theory is one of the crucial components in restoring trust strategies and it explains the trust triangle framework - trustworthiness, distrust, and trust. Within this framework, trust-repair strategies are used to rebuild the trust once broken by corporate. If the trust is violated, as discussed by Fuoli (2014), organizations are encouraged to implement two different types of trust strategies, i.e., emphasize the positive and neutralize the negative. These strategies are aimed at restoring trust by highlighting the trust breaker's benevolence, integrity, and ability.

\subsection{Crisis in the Fast Food Industry}

The fast-food industry has been seeing major crises, particularly in the context of food safety. Uçar, Yilmaz and Cakiroglu's (2016) mentions that fast food industries, that are constantly involved in food crises such as food safety, are likely to suffer from small capacity to respond. Similarly, Hingley et al (2013) found that one of the major crises in the fast-food industry is product harm. The study further defines product harm as well-advertised incidents wherein products are found to defect or harmful for the consumers. This product harm crisis directly impacts the firm's reputation and image in the target market.

Food safety, according to Mohammad et al (2018), is safe handling of food via clean and safe methods to prepare, organize, cook, or serve. The food industry has been experiencing mishandling of food processes that has become a major concern for not only food companies, but also for the food regulatory authorities. Apart from safely handling food, the fast-food industry greatly suffers from cross-contamination, a major food crisis. As mentioned by Nerín, Aznar, and Carrizo (2016), contamination in food is caused due to the transference of microorganisms and bacteria from one food item to another. However, these can be counter by safely handling the food items and following the standards that are set by food regulatory bodies. While discussing food crises, Zhu, Anagondahalli, and Zhang (2017) established that major fast-food giants, like KFC and McDonald, were using Sudan I - red dye- and poisonous oil, respectively. These ingredients are reported to cause cancer to the consumers, as well as other fatal diseases. These incidents significantly impacted customer's perception and overall image of these brands that eventually resulted in decreased sales.

\section{Methodology}

\subsection{Research Approach}

The research approach adopted for the current study is qualitative in nature. The qualitative research approach is deemed appropriate to examine the role of crisis communication as a trust-repair strategy within the industry of Food Establishments, due to its capacity of enabling an in-depth analysis as stated by Fielding (2012). 
The in-depth analysis gives descriptive and narrative results to investigate how the response and trust of consumers of McDonalds and KFC were impacted when the restaurants used different kinds of crisis communication strategy. Taking into account the crisis communication strategies of two different food establishments, in the occurrence of diverse food safety crisis, will help the study to compare and contrast the possible ways which can be undertaken to effectively repair trust of consumers. However, the study does not take into account the quantitative methods of researching the above-stated phenomenon due to its lack of compatibility with the objectives and comparative analysis technique.

\subsection{Research Design}

The determination of the research design is followed by the methodological approach taken into account since research design helps to outline the overall strategy and analytical methods of conducting the research (Bryman and Bell, 2015). Given that the present study integrates qualitative research approach, the researcher implements single research design of case studies which helps to focus, on the crisis communication in relation to food safety crisis and trust-repair strategies, easier. The case study design is also adequate for the study since it includes the employment of diverse observational, analytical, thematic and comparative techniques to evaluate and conclude whether KFC's trust-repair strategies received a positive response from its consumers or McDonalds' strategies of crisis response were more effective to retain its customers' trust. For this reason, the following case studies were undertaken by the research;

- Case Study 1. McDonalds' crisis on March 15, 2012.

- Case Study 2. KFC's crisis on November $23^{\text {rd }}, 2012$.

- Case Study 3. McDonald's' Expired Meat Scandal in 2014.

- Case Study 4. KFC's Expired Meat Scandal 2014.

The cases took place in China; it means the paper emphasizes on crisis communication in China, while the analysis has been done with the help of Trust-Repair Model using Discourse analysis technique.

\subsection{Data Sources}

Considering the current study incorporates case study design in the research process, the data of the study thereby will be collected from secondary sources. Hair (2015) explains that in order to collect data from secondary sources, the researcher should integrate already existing data instead of trying to develop new data. Hence secondary sources include existing data in already published reports, officially updated databases, credible and integral articles as well as organizational records. Consequently, relying on secondary data sources, the researcher combines journal and news articles to identify case studies which provide narrative on McDonalds' and KFC's food safety crisis.

\subsection{Sampling Strategy}

The sampling strategy of the current research provides a broad scope of sample size taken into consideration since the case studies specified above are all the past food safety crisis faced by McDonalds and KFC in China. The study, therefore, emphasizes the research journals and news articles which are published between the year 2012 to 2014. Furthermore, in the planning process of collecting the sample size and data, the researcher ensures credible research journals and news articles, which are published online, are considered only.

\section{Data Analysis and Findings}

\subsection{Descriptions of the Cases}

\section{Case 1}

CCTV footage had been released as on March $15^{\text {th }}$, 2012 which publicly exposed McDonald's outlet which was located in Beijing's Sanlitun area. The footage was one minute and forty-five seconds long undercover report on the unacceptable practices of the restaurant. These include not only selling post expiry chicken fillets, pies and cheeseburgers, but also the selling the burger patties which have fallen on a dirty kitchen floor. The news report spread to around 8400 Weibo accounts reaching more than 10 million users and ultimately turning this into a PR disaster. After thirty minutes of the video being aired on an evening show, the restaurant announced a suspension of the operations of the offending McDonald's Franchise. Within two hours of the public report, McDonald smartly apologized and took responsibility for the unexpected mess one of the restaurants made for them. The apology was made through its microblog which was then reposted nearly twenty thousand times.

\section{Case 2}

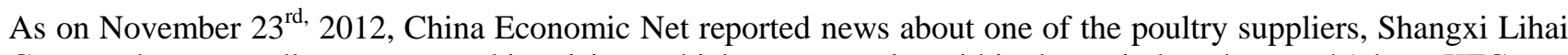
Group, who reportedly was engaged in raising a chicken to maturity within the period as short as 45 days. KFC was quick to respond to the issue by assuring that the Lihai Group contributed only one per cent of the fast food's supply of poultry. 
However, the statement which had been released was not able to retreat back its image as the negative criticism against the brand continued despite the issuance of another statement by KFC assuring that the company has investigated the issue and have found that no evidence had been found against Lihai group unethical practices. The statement also adds KFC explained that raising broiler chicken for the period of 45 days is normal industry norm and is scientifically proven as feeding habits. However, these statements did not appease the public and hence the crisis reached its peak when another CCTV footage of the KFC supplier showed the public that the birds were growing with fed growth hormones in order to speed up the growth process while also increasing the bird's weights. Despite such a piece of visible evidence against KFC's supplier, the brand continued to deny its part in any wrongdoings. Also, a statement by KFC triggered the consumers even more which stated that "if [we] find out that our suppliers have conducted any improper activity, [we] will handle it strictly". This statement raised more negative comments by the consumers of KFC on the microblog and hence in order to lower down the mess, the CEO of Yum under which KFC was operating in China issued an official apology on Jan 10, 2013. However, it was too late. The KFC brand had been mocked all over the microblog and people were wanting the brand to leave China. As a result of this chicken scandal, Yum's profitability dropped by $26 \%$ in the initial quarter of 2013.

\section{Case 3}

McDonald's caught itself trapped in yet another scandal and critical PR crisis in 2014. The crisis mainly occurred in such a situation whereby the meat supplier in China, Shanghai Husi Food Co., was exposed selling expired meat products to one of the biggest food chains in China like McDonald and KFC. On $20^{\text {th }}$ July 2014, the scandal came into the spotlight when a Shanghai television network named Dragon TV, took it to their responsibility to expose the supplier's unethical practices of keeping rotten meat in their production line. This was mainly a seven-minutelong documentary report which also showed the viewers a notice paper requesting for extension of the expiry dates on these products (Jain, 2014). The video footage of the supplier factory also revealed the way workers handled with their food with their bare hands and many incidents of them picking up fallen meat from the floor and using the same for the processing machine without any sort of cleaning practices. When questioned about the employees wearing surgical masks about if the use of foul meat was safe, the person shamelessly replied that people are alive so this meat is no problem while another person quoted a Chinese idiom "corners have been cut" in a very casual behaviour (Almoshiqeh, 2014). After this information has been leaked, McDonald was the first, to respond to the issue via their official account of Weibo. The company publicly issued its apology letter which not only presented a heartfelt apology but also promised to critically investigate this matter and gave guarantee for providing safety and hygiene for its customers (Phillip, 2014). In addition to this, McDonald's invited media, government and also its customers for visiting and examining its kitchen's hygienic conditions. This post had been shared by almost 8400 people and viewed by more than 27 million people within just two hours (McDonald's Chinese Newsroom, 2014). Moreover, the company also reportedly reduced its supply from Shanghai Husi on July $21^{\text {st }}$ and hence notified that the outlets may have scarce products of meat and may create customers' inconvenience. However, this act of Mc Donald reflected their concern towards the safety of its customer. Also, by 24rth of July, McDonald declared discontinuing their services from its supplier Shanghai Husi while continuing its relationship with the OSI group and ensuring the improvement of the quality of its products (McDonald's Chinese Newsroom, 2014).

\section{Case 4}

The meat scandal of the OSI Group affected other brands like KFC and Pizza Hut under the Yum brand. On July $21^{\text {st, }} 2014$, this Shanghai Husi scandal had been made the most viewed topic post on the Weibo reaching over 27 million people while deploring foreign fast-food chain, and monitoring of China's food safety and local media's tendency for making news by going after well famous consumer brands (Kuo, 2014). On the Sina Weibo, the scandal had been referred to as "Husi incident" (Fuxi shijian), "Expiration Gate" (guoqi men), and even "Stinky Meat Gate" (chourou men). The Yum brand Inc., which mainly owns KFC said that OSI is not a major supplier of the restaurants in any region of the world, however, the company did confirm that it will be terminating all agreements with OSI in not only China but also in US and Australia, and it reserves the right for taking legal actions against the OSI (Associated Press, 2014). KFC, however, had been criticized for delayed response for wrongdoing until it has been proven.

\subsection{Trust- Repair Model Analysis}

In order to evaluate the crisis management strategies, trust-repair model has been utilized as a tool for qualitative analysis of each of these cases. In this model, discourse analysis is conducted for establishing communicative action for the damaged trust/brand images. The three-step analysis is studying sought effect, communicative action and the discourse as text.

There are two fundamental discursive strategies which are mainly used by the trust breaker (McDonald's and KFC), with a purpose of achieving its overall aims and goals related to effective communication (Fouli and Paradis, 2014). By acting as a non-trusting source, these trust breakers respond to the actual/potential discourses, which can be termed as neutralizing the negatives. 
In Case 1 and Case 3, McDonald's have used mainly Weibo network to reach out its customers and retaliate the proposed mess in such crisis situation. Using social media has apologized for rebuilding its image and considering the promptest and effective action since such posts immediately spread across a vast number of people and hence is regarded as an effective way for restoration of the brand image. Whereby in case of KFC, the group company Yum Inc used external communication outlets to reach out its customers via its social media pages and news interviews.

Case 1

The immediate response from McDonald in case of the crisis of 2012 was as follows:

We will launch an immediate and serious investigation into this
case, which is rare and alone, and take actions to show our regret
to the customer, "said McDonald's China, "after this event, we will
deepen our management to ensure business codes are in place and
provide safe and health food for the customers" (Green, 2012)

$\underline{\text { Case } 2}$

On the contrary, it has taken KFC weeks to apologize to the Chinese customers from November $23^{\text {rd }}, 2012$ to January $10^{\text {th }}, 2013$. The delayed response of the brand had hindered the reputation of the brand since the response time often has a positive association with the reputational damage in the social-media crisis. Hence KFC's slow response met with strong criticism (Capone, 2013). The initial response to the crisis was in the form of a statement on its microblog stating the following:

\begin{tabular}{l}
$\begin{array}{l}\text { "KFC always attaches great importance to food safety and } \\
\text { asks its chiken providers to take food safety measures } \\
\text { seriously..." }\end{array}$ \\
$\begin{array}{l}\text { "If \{we\} find out that our suppliers have conducted any } \\
\text { improper activity, [ we] will handle it strictly. }\end{array}$ \\
\hline
\end{tabular}

For combating the negative publicity and negative criticism, on January 10, 2013, Samuel Su, the CEO of Yum Inc., posted an open letter of apology on KFC's official microblog.

"we regert our failures, and on behalf of Yum China, l apologizes
sincerely to everyone," Sam Su, Yum China's chief executive said.
"We will use our actions to win people's support back, "the company
statement said. "We will ensure everyone can eat safe chicken at KFC."

$\underline{\text { Case } 3}$

In the year 2014, McDonald publicly issued an official apology through its local Weibo account taking full responsibility for the crisis and depicted rather very prompt communicative actions in case of such an extreme crisis situation. The following response had been taken from an interview of the media relations for Mc Donald, Becca Hary:

"If confirmed, the practice outlined in the report are completely unacceptable to
Mcdonald's, "McDonald responded within $\mathbf{3 0}$ minutes of the issue taking full
responsility while adding more a few minutes later: "We ate no longer serving
produce from the facility. This matter is being thoroughly investigated and we are
cooperating fully with the authourities"

\section{$\underline{\text { Case } 4}$}

In response to the meat scandal of 2014, yum brand Inc., apologized and took action against the crisis immediately as:

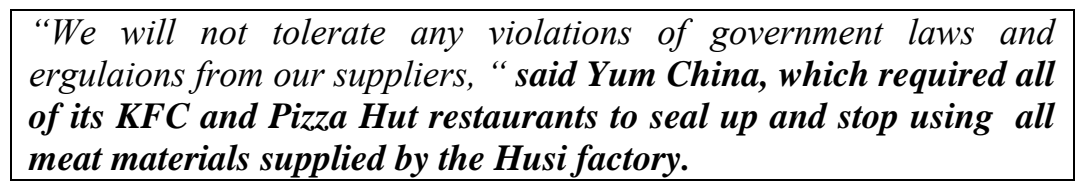

As for the sought effect, it is important to first indicate the crisis's immediate effect and the response to the case. In case of McDonald, the immediate impact of the crisis was seen by the loyal customers in the form of the positive responses from consumer towards the brand. Based on the result of public survey poll that has been conducted on Sina.com that has reflected that more than $80 \%$ of the McDonald's consumers still thought positively about the brand despite the revelation made by the 
CCTV footage whereas only $11 \%$ of the participants reflected prompt trust on the revealed video. According to a response to the public apology statement, the supporter of McDonald responded with following statement:

"In my opinion, the McDonald's [ branch] that was criticized by
CCTV is in fact an exemplar for China's restaurant industry: The
food [providedby the Saniltun branch] was still fresh; it only passed
the expiration period set by the corprtaions itself" (hao chi lan zuo
jia tan shua; March 25, 2012)

In comparison to this, in response to KFC 2012 scandal, one of the customers responded to his discontent in the following way:

"Next time I get sick, I'm going go
KFC.Get my antibiotic fix[ed] from
their chicken- save me a trip to the
hospital!" (Li, 2012).

Moreover, in addition to this, the meat scandal's consumer response in 2014 indicated a very jumbled feeling of customers McDonald and KFC. "Im worried about my health. I will try to avoid it, at least for a while. I am pretty
disappointed in this brand."

While others have shown noncaring attitude towards the news and commented:

"My boyfriend called and told me not to eat McDonald's one minute after I ordered
this chichen hamburger, but what can I do? I 've already ordered and I am in a
hurry,"

On the other hand, some of the comments supported the brands:

"The incident won't change me eating here. There have been negative reports all the time. McDonald and KFC are the leaders in the industry."

Moreover, even after a public apology statement by both McDonalds and KFC, the huge decline in the overall sales of the restaurants had been recorded subject to the damaged consumer sentiments due to such hurtful scandalous event.

As per the discourse as text analysis, the language of the responses or information in context to its meaning is possible for identification of the group of strategy the company has mainly followed to either neutralize the negative or emphasis on the positive aspect of the crisis (Fairclough, 1992).

Table 1: Comparison of brands

\begin{tabular}{|c|c|c|}
\hline Brands & Neutralizing the Negatives & Emphasizing on Positive \\
\hline McDonalds & $\begin{array}{l}\text { In case of McDonald's, the initial statement has } \\
\text { been issued right after the occurrence of the } \\
\text { events in both the cases (Case I and Case 3) } \\
\text { whereby not actually showing their approval or } \\
\text { denial to the unethical claims made via CCTV } \\
\text { footages. In its immediate responses, the use of } \\
\text { words like "If confirmed..." and a statement like } \\
\text { "launch serious investigations... which is rare and } \\
\text { alone..." indicates the company's doubts against } \\
\text { the raised claims. Such treatment are not fully } \\
\text { supporting the negative events and it mat reflect } \\
\text { non- agreement to the leaked foodages from the } \\
\text { supplier and the McDonald's kitchen itself. }\end{array}$ & $\begin{array}{l}\text { While emphasizing on the positives, } \\
\text { the words like "regret" can be taken } \\
\text { ditectly as the imphasizing on the } \\
\text { positives strategy as per the trust } \\
\text { repair model. }\end{array}$ \\
\hline$K F C$ & $\begin{array}{l}\text { In the case of KFC, the company issued responses } \\
\text { which supported the claims and made things } \\
\text { worse for the brand. The words like "If we } \\
\text { find..." and "we will..." indicates the non } \\
\text { agreement to the raised claims.Hense,the negative } \\
\text { could not be neutralizing via these statements. }\end{array}$ & $\begin{array}{l}\text { In the other hand, in response to case } \\
4, \text { KFC issued avery delayed apology } \\
\text { stating words like. "we will..." And } \\
\text { "not tolerate..." as a positive } \\
\text { emphasis strategy. However, since the } \\
\text { response was made very late, the } \\
\text { brand was unable to retaliate from the } \\
\text { crisis as quick as McDonald's had. }\end{array}$ \\
\hline
\end{tabular}

\section{Conclusion}

The aim of this report is to asses and investigates different crisis communication strategies employed by fast-food chains in case of unexpected crisis. Various researches have been found in relation to the firm's responsiveness 
towards the food safety crisis in past literature. The current study mainly contributes to the existing scholarship with a different angle by providing a comparative analysis on two widely established fast-food brands. The aforementioned research mainly presents a successful elaboration of the response strategies of both the brands with an aim to regain the customer's trust and restoration of their positive brand image across the world. Furthermore, the study also compares the strategies in relation to the responses the company has received after and before the apology statements have been issued by the company.

For carrying out this research, the current study uses a qualitative research design for exploring different communication strategies and assessing their impact. Along with this, the discourse analysis has been performed under the trust repair model to analyses and compare different ways in which food safety crisis have been handled by both the brands. The study is mainly accustomed by external sources of news articles and journal articles.

In addition to this, the study mainly highlights four cases of the crisis management strategies of the two brands in China in the year 2012 and 2014. It is found that comparatively, the immediate response strategy of McDonald's in both the years helped the brand in retaliating back to its successful operations and positive image despite such harsh accusations made. The consumer appreciated the prompt response and apology from the brand's side and hence not much harm was seen in context to McDonald's profitability. Whereas, in the case of KFC, the brand found itself in a very unsatisfactory position as the brand in 2012 firstly supported the problematic supplier's case and go about telling people that there was nothing wrong. Moreover, the delayed response apology in case of the meat scandal 2014 made it impossible for the company to regain its image since both McDonalds and KFC were victim of similar cases. People of China found McDonald's apology statement to be genuine and prompt while KFC took a year to regain its status in the fast-food market.

Finally, the limitations of the study are the limited cases and the limited areas for conducting the study.

The authors recommend using variables and other factors in the crisis communication such as the use of social media to communicate with customers and choose the appropriate time to communicate and response while maintaining the reputation and image of the organization especially in the time of Corona disease and the risks and surprises that arise in the organizations.

\section{References}

Almoshiqeh, A. (2014). McDonald's Corporation Memo RE: Shanghai Husi Crisis. Blogs. Retrieved from: http://blogs.longwood.edu/ahmadalmoshiqeh/files/2015/03/media-monitoring.pdf

Ardèvol-Abreu, A., 2015. Framing theory in communication research. Origins, development and current situation in Spain. Revista Latina de Comunicación Social, (70). DOI: 10.4185/RLCS-2015-1053

Associate Press. (2014). Meat supplier in China scandal has a global reach. Retrieved from: http://www.dailymail.co.uk/wires/ap/article2703263/Meat-supplier-China-scandal-global-reach.html

Bryman, A., and Bell, E., 2015. Business research methods. Oxford University Press, USA

Buklemishev Oleg V.(2020), Coronavirus crisis and its effects on the economy, Population and Economics 4(2): 13-17 DOI 10.3897/popecon.4.e53295

Capone, V. (2013). After the Shanghai government finding leads to P.R. crisis, KFC's online apology falls flat. In Tea Leaf Nation. Retrieved from: http://www.tealeafnation.com/2013/01/after-shanghai-governmentfinding-leads-to-p-r-crisis-kfcs-online-apology-falls-flat/

Cheek, J. (2004). At the margins? Discourse analysis and qualitative research. Qualitative health research, 14(8), pp.1140-1150.

Claeys, A.S. and Cauberghe, V., 2012. Crisis response and crisis timing strategies, two sides of the same coin. Public Relations Review, 38(1), pp.83-88.

Claeys, A.S. and Cauberghe, V., 2014. What makes crisis response strategies work? The impact of crisis involvement and message framing. Journal of Business Research, 67(2), pp.182-189.

Claeys, A.S., Cauberghe, V. and Leysen, J., 2013. Implications of stealing thunder for the impact of expressing emotions in organizational crisis communication. Journal of Applied Communication Research, 41(3), pp.293-308.

Coombs, W.T., 2014. Ongoing crisis communication: Planning, managing, and responding. Sage Publications.

Coombs, W.T., 2015. The value of communication during a crisis: Insights from strategic communication research. Business Horizons, 58(2), pp.141-148.

Coombs, W.T., Holladay, S.J. and Tachkova, E. (2019). Crisis Communication, Risk Communication, and Issues Management. Public Relations Theory: Application and Understanding, p.31.

Fairclough, N. (1992). Discourse and text: Linguistic and intertextual analysis within discourse analysis. Discourse \& Society, 3(2), 193-217.

Fehrenbacher, D.D., 2016. Perceptions of information quality dimensions from the perspective of commodity theory. Behaviour \& Information Technology, 35(4), pp.254-267.

Fielding, N.G., 2012. Triangulation and mixed methods design: Data integration with new research technologies. Journal of mixed methods research, 6(2), pp.124-136. 
Fuoli, M. (2012). Assessing social responsibility: A quantitative analysis of Appraisal in BP's and IKEA's social reports. Discourse \& Communication, 6(1), 55-81.

Fuoli, M. and Paradis, C., 2014. A model of trust-repair discourse. Journal of Pragmatics, 74, pp.52-69.

Fuoli, M., 2014. Towards a model of trust-repair discourse. In Fifth international conference Critical Approaches to Discourse Analysis across Disciplines (CADAAD).

Gärdenfors, P. (2014). The geometry of meaning: Semantics-based on conceptual spaces. MIT Press.

Gillespie, N. and Dietz, G., 2009. Trust repair after an organization-level failure. Academy of Management Review, 34(1), pp.127-145.

Greene, S. (2012). Broadcast Prompts Apologies from McDonald's, Carrefour. China Digital Times. Retrieved from: https://chinadigitaltimes.net/2012/03/broadcast-prompts-apologies-from-mcdonalds-carrefour/

Hair, J. F., 2015. Essentials of business research methods. ME Sharpe.

Hingley, M., Lindgreen, A., Reast, J., Assiouras, I., Ozgen, O. and Skourtis, G., 2013. The impact of corporate social responsibility in the food industry in product-harm crises. British Food Journal.

Hu, W., and Xie, Y., 2013. Comparative study of Mc Donalds and Kentucky Fried Chicken (KFC) development in China.

Jain, A. (2014). China Food Scandal rocks McDonalds and KFC. PR-Week. Retrieved from: https://www.prweek.com/article/1304517/china-food-scandal-rocks-mcdonalds-kfc

Janoske, M.L., Liu, B.F. and Madden, S., 2013. Congress report: Experts' recommendations on enacting best practices in risk and crisis communication. Journal of Contingencies and Crisis Management, 21(4), pp.231-235.

Kim, S. and Sung, K.H., 2014. Revisiting the effectiveness of base crisis response strategies in comparison to reputation management crisis responses. Journal of Public Relations Research, 26(1), pp.62-78.

Kuo, L. (2014). KFC, Pizza Hut, and McDonald's are hit with a new China food scandal: expired meat products. Quartz.

Lankton, N., McKnight, D.H. and Thatcher, J.B., 2014. Incorporating trust-in-technology into Expectation Disconfirmation Theory. The Journal of Strategic Information Systems, 23(2), pp.128-145.

Ma, L. and Zhan, M., 2016. Effects of attributed responsibility and response strategies on organizational reputation: A meta-analysis of situational crisis communication theory research. Journal of Public Relations Research, 28(2), pp.102-119.

McDonald's Chinese Newsroom. (2014). McDonald's Corporation. Retrieved from: http://www.mcdonalds.com.cn/cn/ch/index.htm

McEvoy, J.D., 2016. Emerging food safety issues: An EU perspective. Drug testing and analysis, 8(5-6), pp.511520.

McMurphy, S., 2013. Trust, distrust, and trustworthiness in argumentation: Virtues and fallacies.

Mohammad, A.M., Chowdhury, T., Biswas, B. and Absar, N., 2018. Food Poisoning and Intoxication: A Global Leading Concern for Human Health. In Food Safety and Preservation (pp. 307-352). Academic Press.

Mørkbak, M., Christensen, T. and Gyrd-Hansen, D., 2010. Consumer preferences for safety characteristics in pork. British Food Journal, 112(7), pp.775-791.

Nerín, C., Aznar, M. and Carrizo, D., 2016. Food contamination during food process. Trends in food science \& technology, 48, pp.63-68.

Palmieri, R. and Musi, E., 2019. Trust-oriented argumentation in rhetorical sub-arenas: from corporate communication to online stakeholder discussions. The "The Facts About Facebook" case.

Phillip. (2014). McDonald's PR crisis. Marketing to China. Retrieved from: http://marketingtochina.com/prcrisissolution-online-mcd/

Sellnow, T.L. and Seeger, M.W., 2013. Theorizing crisis communication (Vol. 4). John Wiley \& Sons.

Steelman, T.A. and McCaffrey, S., 2013. Best practices in risk and crisis communication: Implications for natural hazards management. Natural hazards, 65(1), pp.683-705.

Timothy Coombs, W. and Jean Holladay, S., 2014. How publics react to crisis communication efforts: Comparing crisis response reactions across sub-arenas. Journal of Communication Management, 18(1), pp.40-57.

Uçar, A., Yilmaz, M.V. and Cakiroglu, F.P., 2016. Food Safety-Problems and Solutions. Significance, Prev Control Food Relat Dis, pp.3-15.

Utz, S., Schultz, F. and Glocka, S., 2013. Crisis communication online: How medium, crisis type and emotions affected public reactions in the Fukushima Daiichi nuclear disaster. Public Relations Review, 39(1), pp.4046.

Veil, S.R. and Husted, R.A., 2012. Best practices as an assessment for crisis communication. Journal of Communication Management, 16(2), pp.131-145.

Wu, Y. and Ding, J., 2014. The research of crisis communication strategies in food safety: A comparative case study between Sanlu and IKEA.

Yan, J. 2011. Fonterra in the San Lu milk scandal-a case study of a New Zealand company in a pro duct-harm crisis. Lincoln University Digital Dissertation. 
Yeung, R. and Yee, W.M., 2012. Food safety concern: Incorporating marketing strategies into consumer risk coping framework. British Food Journal, 114(1), pp.40-53.

Zhu, L., Anagondahalli, D. and Zhang, A., 2017. Social media and culture in crisis communication: McDonald's and KFC crises management in China. Public Relations Review, 43(3), pp.487-492. 